\title{
Redimensionar simbólicamente el Holocausto: álbumes ilustrados para su abordaje en Educación Primaria
}

\author{
Resizing Symbolically the Holocaust: Picture Books for its approach in Elementary Education \\ Leonor Ruiz-Guerrero*, Sebastián Molina-Puche*
}

\section{Resumen}

Donde la palabra se torna insuficiente y la realidad se vuelve inenarrable, la imagen y la ficción pueden convertirse en el único resquicio para contar lo que debe ser contado. Es por ello que el álbum ilustrado se revela como idóneo para abordar la cuestión del Holocausto con un público infantil y juvenil (Bieber, 2018; Kidd, 2005; Walter y March, 1993). Este artículo presenta el análisis de los rasgos definitorios de los álbumes con tal temática mediante el estudio de un corpus de cuatro ejemplos, y ahonda en las posibilidades didácticas de un título en particular, Bruno. El niño que aprendió a volar, de Nadia Terranova y Ofra Amit (2012). Los resultados nos hacen concluir que es posible crear desde el lirismo imágenes para enseñar la más infame atrocidad.

Palabras clave: Holocausto. Álbum ilustrado. Educación Primaria. Bruno. El niño que aprendió a volar. Lirismo.

\begin{abstract}
Where the word becomes insufficient, and reality becomes unspeakable, the image and fiction can become the only chink to tell what must be told. That is why picture books are revealed to be suitable for addressing the Holocaust issue with young audiences (Bieber, 2018; Kidd, 2005; Walter y March, 1993). This paper presents the analysis of the defining features of picture books dealing with this topic through the study of a corpus of four examples. It delves into the didactic possibilities of a particular title, Bruno. El niño que aprendió a volar, by Nadia Terranova and Ofra Amit (2012). Results make us conclude that it is possible to create images from lyricism to teach the vilest outrage.
\end{abstract}

Key words: Holocaust. Picture book. Elementary Education. Bruno. El niño que aprendió a volar. Lyricism. * Universidad de Murcia • L. Ruiz-Guerrero (ORCID 0000-0003-1520-8368). S. Molina-Puche (ORCID
0000-0003-1469-2100) • Autora de correspondencia: Leonor Ruiz-Guerrero (Imruiz@um.es).

Ruiz-Guerrero, L. y Molina-Puche, S. (2020). Redimensionar simbólicamente el Holocausto: álbumes ilustrados para su abordaje en Educación Primaria. CLIO. History and History teaching, 46, 110-121. https://doi.org/10.26754/ojs clio/clio.2020465279. Recibido: 10/9/2020. Aceptado: 4/12/2020. 


\section{Introducción}

El final de la Segunda Guerra Mundial trajo consigo una reflexión profunda y crítica sobre las expresiones culturales europeas y su función tras Auschwitz. Con el foco puesto en la moralidad o posibilidad de crear literatura sobre el Holocausto se abrió un debate que se ha mantenido hasta prácticamente nuestros días (Fernández Gil, 2013; Walter y March, 1993). Se planteaba la necesidad de límites (Fernández, 2006), y se percibía como especialmente conflictivo el "desafío de la ficción” (Fernández, 2006). E temor con respecto a esta se articulaba en torno a si el convertir en literatura hechos reales de la magnitud de los acontecidos conduciría a desvirtuar su verdad (Fernández Gil, 2013; Kokkola, 2013; Walter y March, 1993). Asimismo, se temía que pudiese servir para reforzar el discurso negacionista del Holocausto (Kokkola, 2013). Sin embargo, esta posición simplificaba la naturaleza de lo literario y negaba valor subversivo a la ficción, refutando su potencial para hacer inteligible el horror y para provocar la catarsis (Fernández, 2006; Fernández Gil, 2013; Kertész, 2002). Los límites demandados se generan justamente en uno de los rasgos propios de la ficción, su anclaje en la realidad. Las ficciones sobre el Holocausto asientan su compromiso ético y honestidad huyendo de la distorsión mediante una rigurosa documentación histórica (Bieber, 2018; Fernández, 2006; Kokkola, 2013).

Quizás solo internándonos en el campo de la ficción seamos capaces de hacer verosímil un relato para el que el testimonio real encarnado en las palabras puede resultar insuficiente. $Y$ no por la debilidad de la historia en sí, no por la falta de fiabilidad de quien narra aquello que realmente ocurrió, sino porque la dimensión del hecho lo vuelve inexpresable e increíble. Por eso, a la emergencia de los textos autobiográficos y testimoniales de entidad no literaria se unió la literatura "que, ante la necesidad de hablar de una realidad que sobrepasa la imaginación, recurrió a la ficción y a la simbología como mecanismos para superar la inefabilidad." (Fernández Gil, 2013, p. 13).

La superación del debate ha venido de la mano de la constatación de que no hay una sola vía para preservar la memoria del Holocausto, así como de que la imaginación y la Historia no son campos antagónicos (Fernández Gil, 2013; Ruiz-Guerrero, 2015). 
Al amparo de esa generación literaria de anamnesis también han surgido textos dirigidos al público infantil y juvenil, sobre todo desde el inicio de la década de los noventa, cuando comenzó a verse la literatura infantil y juvenil (en adelante LIJ) como un espacio idóneo para trabajar el trauma (Kidd, 2005). Estas obras se alejan de los parámetros convencionales de la LIJ (Walter y March, 1993), ya que no suelen seguir la premisa de presentar una visión optimista del mundo; no muestran una resolución de la situación; ni aportan un horizonte de esperanza (Kokkola, 2013; Walter y March, 1993). Esta ubicación fuera de los límites normales de la LIJ sería entonces una de las cualidades de este tipo de literatura del Holocausto para público infantil y juvenil, a la que se sumarían el tema desafiante y la responsabilidad ética (Kokkola, 2013).

Dentro de los textos LIJ de ficción, en el presente estudio el interés se centra en el género álbum ilustrado, ya que se postula como apropiado para afrontar la comprensión del Holocausto (Bieber, 2018; Kidd, 2005; Walter y March, 1993). Precisamente porque es capaz de sobreponerse a la limitación de las palabras, completándolas con imágenes que van desde lo realista a lo abstracto y simbólico. Cuando se considera el tratamiento del Holocausto en ese tipo de obras el primer título que suele nombrarse es Rosa Blanca, de Christophe Gallaz y Roberto Innocenti (primera edición 1985), pionero en abordar tal cuestión y referente en el ámbito de la investigación (Baer, 2000; Kidd, 2005; Kokkola, 2013; Walter y March, 1993.). Empero, hay literatura sobre el Holocausto más allá de Rosa Blanca. En este estudio se analizan otros cuatro títulos con el objetivo de extraer los rasgos definitorios de este tipo de textos, incidiendo en el valor de las ilustraciones para ayudar a elaborar un imaginario de lo inefable. Tras el análisis se atiende a las posibilidades didácticas del género, ahondando en uno de los álbumes.

\section{Metodología}

Corpus seleccionado

Los cuatro álbumes analizados fueron publicados entre finales del siglo XX y principios del XXI. Los tres primeros comparten voz narrativa: primera persona, mientras que en el cuarto se emplea la tercera. En todos ellos hay una fuerte presencia del mundo infantil. Además, quienes los han creado tienen una relación directa o indirecta con el 
tema de sus obras: Ungerer e Innocenti lo vivieron en primera persona; mientras que Concejo es polaca y Amit israelí.

Otto. Autobiografía de un osito de peluche (en adelante Otto), de Tomi Ungerer (primera edición 1999). En él un osito de peluche relata una relación de amistad entre él y dos niños, uno de ellos judío. La llegada de los nazis al poder determinará sus vidas.

La historia de Erika, de Ruth Vander Zee y Roberto Innocenti (primera edición 2003). En él la protagonista cuenta su experiencia de desarraigo con respecto a su identidad judía, al haber sido apartada de su familia para salvarla del Holocausto.

Humo, de Antón Fortes y Joanna Concejo (primera edición 2008). Un niño de entre seis y ocho años narra su vida en un campo de concentración.

Bruno. El niño que aprendió a volar (en adelante Bruno), de Nadia Terranova y Ofra Amit (primera edición 2012). Este texto narra la vida del escritor y artista plástico polaco Bruno Schulz, desde su infancia hasta su asesinato por un oficial nazi.

\section{Análisis de los álbumes seleccionados}

La primera cualidad que debe resaltarse de estos álbumes es que son obras de ficción, incluso en los casos en los que se tiene como punto de partida un testimonio o personaje real, como podría ser La historia de Erika o Bruno. Pese a ello, aquello que cuentan ocurrió, o pudo ocurrir, y el ejercicio de documentación que los textos revelan, tanto en la parte verbal como en la visual, es suficiente para conferir legitimidad a lo narrado. Esa referencia a lo real, su enraizamiento en el hecho histórico es clave para determinar el valor de estas obras, pues es lo que impide que se produzca una quiebra entre lo acontecido y la ficción que lo representa (Fernández, 2006).

Tras esta primera consideración, las categorías que se han tenido en cuenta para el análisis han sido: presencia de términos específicos ligados al Holocausto; presencia de elementos propios del marco referencial; representación de la muerte; y símbolos y alegorías. 


\section{Resultados y discusión}

Presencia de términos específicos ligados al Holocausto

En esta categoría se analiza el empleo de palabras claramente vinculadas al Holocausto, como pueden ser "judío", "nazi", "gueto", o "campo de concentración". Son términos que facilitan la contextualización de la historia, aunque a menudo su significado no sea evidente en el texto o las imágenes, y se dé por conocido (Tabla 1).

\begin{tabular}{|l|l|l|l|l|}
\hline & Otto & H. de Erika & Humo & Bruno \\
\hline Holocausto & & X & & \\
\hline Guerra & X & X & & X \\
\hline Judío/s & X & X & & X \\
\hline Estrella de David & X & X & & \\
\hline Nazi & & & & X \\
\hline Gueto & & $X$ & & \\
\hline Campo de concentración & $\mathrm{X}$ & $\mathrm{X}$ & & \\
\hline Superviviente & $\mathrm{X}$ & & & \\
\hline Deportación & $\mathrm{X}$ & & & \\
\hline Hornos crematorios & & $\mathrm{X}$ & & \\
\hline
\end{tabular}

Tabla 1. Presencia de términos específicos ligados al Holocausto.

A estos términos se unen otros indicios en la parte verbal, como la ubicación geográfica (Alemania en el caso de Otto y La historia de Erika, Polonia en Bruno) o temporal ("entre 1933 y 1945" en La historia de Erika, y "1945" en Bruno). También en La historia de Erika se alude al número de asesinados judíos: "seis millones" (Vander Zee, 2005, s.p.).

La ausencia de términos en Humo parece justificada por la voz infantil que desarrolla el relato. No obstante, se emplean otras palabras y expresiones asimilables, como "guardias", "soldados", "alambrada" o "la casa de la chimenea". 
Dentro de esta categoría hay dos aspectos que llaman la atención, por un lado la casi nula referencia explícita al nazismo, que solo aparece en Bruno y de una manera un tanto peculiar: "Y un día, en Drohobycz, se presentaron los nazis" (Terranova, 2012, s.p.). Por otro, solo en Otto se aclara, de modo muy sintético, "qué es judío", cuando Oskar, el protagonista que no lo es interroga a su madre acerca de la estrella de David de su amigo. Ella le explica no solo el significado, sino cómo "el gobierno" trata a quienes lo son, algo que le parece injusto y la apena (Ungerer, 2011, s.p.).

\section{Presencia de elementos propios del marco referencial}

En esta categoría la atención se centra en las ilustraciones, para apreciar si se incluyen elementos que apunten de manera directa o indirecta al marco de referencia (Tabla 2).

\begin{tabular}{|l|l|l|l|l|}
\hline & Otto & H. de Erika & Humo & Bruno \\
\hline Estrella de David & $\mathrm{X}$ & $\mathrm{X}$ & & \\
\hline Campo de concentración (recinto) & & $\mathrm{X}$ & $\mathrm{X}$ & \\
\hline Uniformes rayados & & & $\mathrm{X}$ & \\
\hline Numeración & & & $\mathrm{X}$ & \\
\hline Soldados & $\mathrm{X}$ & $\mathrm{X}$ & & $\mathrm{X}$ \\
\hline Esvástica & $\mathrm{X}$ & & & \\
\hline Trenes & & $\mathrm{X}$ & $\mathrm{X}$ & \\
\hline Maletas & $\mathrm{X}$ & $\mathrm{X}$ & $\mathrm{X}$ & \\
\hline
\end{tabular}

Tabla 2. Presencia de elementos propios del marco referencial.

El modo en que han sido representados estos elementos revela una intención más allá de la mera exposición. La práctica ausencia de la esvástica, unida a la omisión señalada en el apartado anterior, parece responder a una pretensión de no otorgar un protagonismo inmerecido a los ejecutores, inclinando el peso del relato hacia las víctimas y su humanidad. Con este fin, no hay imágenes cruentas de los campos, y los 
textos ponen el acento en el valor de las relaciones humanas (la familia, los amigos). La atrocidad encuentra aquí vías más sutiles de expresión. En Humo, por ejemplo, los números de las listas se van tachando conforme pasan las páginas.

\section{Representación de la muerte}

Dada la temática de estos álbumes la muerte difícilmente puede ser omitida, así que en esta categoría se contemplan las diferentes estrategias para incorporarla. En todo caso, vemos que en estos álbumes la representación se acoge a la concepción del teatro griego clásico de la "muerte obscena". Solo en Otto vemos cadáveres, los de los soldados y civiles caídos en la guerra. Los resultados se exponen en la Tabla 3:

\begin{tabular}{|l|l|l|l|l|}
\hline & Otto & H. de Erika & Humo & Bruno \\
\hline Se cuenta en la parte verbal & $\mathrm{X}$ & $\mathrm{X}$ & $\mathrm{X}$ & $\mathrm{X}$ \\
\hline Se cuenta en la parte visual & $\mathrm{X}$ & & $\mathrm{X}$ & $\mathrm{X}$ \\
\hline Muere el protagonista & & & $\mathrm{X}$ & $\mathrm{X}$ \\
\hline Mueren otras personas & $\mathrm{X}$ & $\mathrm{X}$ & $\mathrm{X}$ & $\mathrm{X}$ \\
\hline
\end{tabular}

Tabla 3. Representación de la muerte.

En Otto la parte verbal cuenta, en pasado, la muerte de los padres de los dos niños, en un campo de concentración, en la guerra y en un bombardeo. En La historia de Erika también se dan este tipo de detalles al narrar la masacre del pueblo judío. En cambio, tanto en Humo como en Bruno se recurre a la alegoría y el simbolismo para evidenciar las muertes. Si se trata de otros personajes, en Humo se hace a través de figuras de papel plegadas, trajes vacíos atrapados en redes y maniquíes infantiles desmembrados. En Bruno, los cuerpos de los desaparecidos cubren el cielo, mientras que la figura del padre se recorta del conjunto de los elementos que formaban su mundo. La muerte de los protagonistas se anticipa, sin revelarse, en Humo, en un final abrupto que aproxima más a la realidad del Holocausto, pero que deja un atisbo de luz en esa mano amiga que no abandona. En Bruno el texto habla de que Schulz se esfumó provocando el estupor de sus ejecutores, mientras que en la ilustración vemos 
la sombra de su asesino con el arma, un sombrero en el suelo, y un cielo que parece sangrar sobre los edificios. Como si el protagonista hubiera podido burlar la muerte. Al final del álbum, él y su padre reaparecen en un plano simbólico, convertidos en niño y pájaro.

\section{Símbolos y alegorías}

Aunque en unos en mayor grado que en otros, en estos álbumes hay un uso de recursos de esta índole, de los que esta categoría da cuenta (Tabla 4).

\begin{tabular}{|l|l|l|l|l|}
\hline & Otto & H. de Erika & Humo & Bruno \\
\hline Naturaleza asociada a renacimiento & & $\mathrm{X}$ & $\mathrm{X}$ & $\mathrm{X}$ \\
\hline Animalización simbólica & & & $\mathrm{X}$ & $\mathrm{X}$ \\
\hline Metáforas visuales para lo atroz & & $\mathrm{X}$ & $\mathrm{X}$ & $\mathrm{X}$ \\
\hline Prosopopeya & $\mathrm{X}$ & & & \\
\hline Variaciones en el color & & $\mathrm{X}$ & $\mathrm{X}$ & \\
\hline Universo simbólico propio & & & & $\mathrm{X}$ \\
\hline
\end{tabular}

Tabla 4. Recursos simbólicos y alegóricos.

La naturaleza empleada como símbolo de esperanza y renacimiento se muestra en Humo cuando infinidad de flores rodean a la madre del protagonista tras poder ver a su marido. En Bruno se manifiesta como enorme girasol que surge tiempo después en el lugar donde el personaje fue asesinado. Mientras que en La historia de Erika se aprecia en la doble página final, con un paisaje que contrasta con los de las páginas previas.

La animalización se da a través de humanos transformados en pájaros, que en el caso de Bruno representan al padre del protagonista, y en Humo a los guardias convertidos en cuervos acechantes. En estos dos álbumes las metáforas visuales, el simbolismo y las alegorías aparecen desde la misma cubierta, y son una constante a lo largo de toda la obra, encarnando lo atroz sin caer en lo brutal. Lo cotidiano y lo simbólico se 
entremezclan para revelar/rebelarse ante un mundo demasiado cruel. Pájaros estampados en un rollo de tela que vuelan lejos; barcos de papel en un cubo de agua después derramada; cabezas humanas mezcladas con patatas crudas; un dragón verde que quiere devorar al protagonista; etc. En La historia de Erika, por su parte, la metáfora visual más destacada es el cochecito de bebé abandonado junto al tren.

En Otto se recurre a la prosopopeya, con un oso ingenuo que sirve de trasunto de la infancia dañada. A su vez, en La historia de Erika las variaciones en el color simbolizan el contraste entre la muerte y la vida, destacando la doble página final.

Por último, en Bruno el universo simbólico expuesto parte de la propia obra de Schulz, estudiada al detalle por Terranova y Amit (2012). Las alusiones al padre y su enfermedad, al ama de llaves, a las metamorfosis y los pájaros beben de Las tiendas de color canela, donde el escritor entreteje aspectos de su vida familiar y de su mundo ficticio y mítico, rayano en lo surrealista y kafkiano (Maldoror Ediciones, s.f.).

Vistas las categorías, se observa una inclusión recurrente de términos específicos y de elementos del marco referencial, que presume que el público lector los reconocerá para ubicar históricamente el relato. Por otra parte, la elipsis, verbal o visual, así como el imaginario simbólico intentan reducir el impacto de la inhumanidad narrada.

\section{Enseñar el Holocausto}

En el año 2013 se incorpora por primera vez al sistema educativo español el estudio del Holocausto judío como hecho histórico en todas las etapas de la Educación Básica (LOMCE, 2013, p. 97914). En la etapa de Educación Primaria aparece tanto dentro de los Elementos transversales como en la asignatura de Valores Sociales y Cívicos, priorizando su análisis como hecho discriminatorio.

Dentro de esta etapa, el segundo tramo parece el más idóneo para su abordaje, ya que se estima que es a partir de los once años cuando se puede entender la complejidad del Holocausto (Walter y March, 1993). No obstante, incluso entonces, el alumnado debe ser expuesto a variedad de textos (Baer, 2000; Kokkola, 2013; Walter y March, 1993), imágenes y otro tipo de materiales, promoviéndose una intensa discusión sobre los mismos (Derevensky, 1987-88, citado en Walter y March, 1993). 
Otro factor que debe tenerse en cuenta, además de la capacidad cognitiva, es el conocimiento previo sobre los hechos narrados, que en estas edades es escaso o inexistente.

Considerando estas circunstancias, en el presente trabajo se sugiere una secuencia para el citado segundo tramo articulada en torno a la lectura de Bruno. Es este un álbum que ha sido objeto de una menor atención, quizás por su relativamente reciente aparición. Tiene un estilo narrativo que difiere de los demás, y que podría resumirse en tres notas: trata de un personaje real, Bruno Schulz, cuya biografía puede rastrearse; tiene una carga alegórica cercana a la de Humo, pero que se mueve en otra dirección; y por último, se centra en la idea de discriminación, por lo que se acerca más a lo que se pretende en los sistemas educativos al abordar el Holocausto.

Es reseñable, además, que en las páginas del título de esta obra se nos diga que se trata de un cuento, ya que esa simple afirmación nos indica claramente hacia dónde se orientan las autoras, cuál es su intención. Pues los cuentos siempre tienen un sustrato de verdad, pero a su vez permiten la introducción del elemento maravilloso. En ellos se permiten salidas y soluciones a los conflictos que serían inverosímiles en la vida real. El cuento permite la rebelión contra la atrocidad. Si Schulz fue cruelmente asesinado por un oficial de las SS, en el cuento de Terranova y Amit se produce el prodigio de su desaparición y reencarnación en el niño que fue (Figura 1).

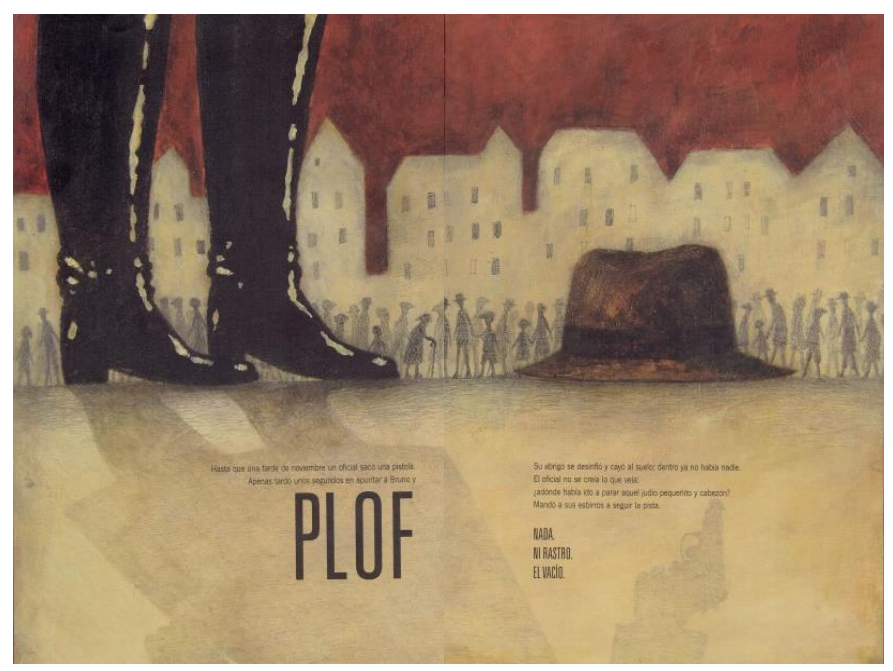

Figura 1. Doble página de Bruno. El niño que aprendió a volar: asesinato de Schulz (A buen paso, 2012). 
En la secuencia didáctica que se propone la discusión tiene un papel preponderante, ya que es la que va a posibilitar al alumnado exponer sus dudas e impresiones sobre el álbum. Esta actividad dialógica se va a apoyar en las categorías de análisis enunciadas, con ello focaliza en los mecanismos específicos empleados en los álbumes, de manera que conecta lo literario/ficcional con la realidad del Holocausto, posibilitando una retroalimentación que haga más comprensibles unos y otra. De este modo, se sugiere una primera sesión de lectura en voz alta del álbum, seguida de una discusión de carácter exploratorio, en la que se guíe al alumnado en el descubrimiento de términos, elementos, etc. En esta conversación se animará a exponer sus propias ideas e hipótesis sobre el texto, sin corregirlas ni completarlas, sino dando pie a la interacción dentro del grupo. En una segunda sesión se produce la introducción de los contenidos sobre el Holocausto. $Y$ de nuevo se retoma el álbum, para que en pequeños grupos se realice una búsqueda supervisada de información sobre Bruno Schulz, a partir de los elementos simbólicos presentes en el libro. Por último, en una sesión final, se promueve una nueva discusión grupal en la que se pongan en contexto los hallazgos, se compartan las interpretaciones sobre el álbum, y se reflexione sobre la discriminación (individual y colectiva) y sus consecuencias.

\section{Conclusiones}

Tras el análisis de los cuatro textos parece claro que los álbumes pueden funcionar como un recurso óptimo para el abordaje del Holocausto en las aulas de Educación Primaria, al proporcionar mecanismos que ayuden a comprender la magnitud de lo acontecido desde un ámbito distinto al de la fotografía y el testimonio directo. El diálogo entre texto e ilustraciones procura una aproximación a la terribilidad del pogromo desde una perspectiva asumible y no lesiva para el público lector. Esto es puesto de manifiesto de manera destacable en el álbum de Terranova y Amit (2012), donde la ficción y la simbología se convierten en las principales vías para escapar del horror. 


\section{Referencias}

Baer, E.R. (2000). A New Algorithm in Evil: Children's Literature in a Post-Holocaust World. The Lion and the Unicorn 24(3), 378-401. https://doi.org/10.1353/uni.2000.0026

Bieber, A. (2018). Voices from the Interior: Reimagining Childhood under Janusz Korczak's Care. The Lion and the Unicorn 42(3), 321-337. https://doi.org/10.1353/uni.2018.0030

Fernández, J. A. (2006). En los límites de lo indecible. Representación artística y catástrofe. $A$ Parte Rei. Revista de Filosofía, 48, 1-12.

Fernández Gil, M. J. (2013). El papel est(ético) de la literatura en la conmemoración del Holocausto. Dykinson.

Fortes, A. (2008). Humo (J. Concejo, llus.). OQO.

Gallaz, C. e Innocenti, R. (1987). Rosa Blanca. Lóguez.

Kertész, I. (2002). Imre Kertész - Nobel Lecture. https://www.nobelprize.org/prizes/ literature/2002/kertesz/25364-imre-kertesz-nobel-lecture-2002-2/

Kidd, K. B. (2005). ' $A$ ' is for Auschwitz: Psychoanalysis, Trauma Theory, and the 'Children's Literature of Atrocity.' Children's Literature, 33, 120-149. http://doi.org/doi:10.1353/ chl.2005.0014

Kokkola, L. (2013). Representing the Holocaust in Children's Literature. Routledge.

Ley Orgánica 8/2013, de 9 de diciembre, para la mejora de la calidad educativa. Boletín Oficial del Estado, 295, 10 de diciembre de 2013, pp. 97858-97921.

Maldoror Ediciones (s.f.). Las tiendas de canela fina. http://www.maldororediciones.eu/ opera omnia/tiendas.htm

Ruiz-Guerrero, L. (2015). Un recurso en los márgenes de lo visible. Los álbumes ilustrados y su aplicación en la enseñanza de las Ciencias Sociales. En A. Hernández, C. R. García y J. L. de la Montaña (Coords.), Una enseñanza de las ciencias sociales para el futuro: Recursos para trabajar la invisibilidad de personas, lugares y temáticas (pp. 585591). Universidad de Extremadura / AUPDCS.

Terranova, N. (2012). Bruno. El niño que aprendió a volar (O. Amit, llus.). A buen paso.

Ungerer, T. (2011). Otto. Autobiografía de un osito de peluche (T. Ungerer, llus.). Ediciones B.

Vander Zee, R. (2005). La historia de Erika (R. Innocenti, Ilus.). Kalandraka.

Walter, V. A., y March, S. F. (1993). Juvenile Picture Books about the Holocaust: Extending the Definitions of Children's Literature. Publishing Research Quarterly, Fall, 36-51. https://doi.org/10.1007/BF02680641 